\title{
DEVELOPMENT AND USE OF SIMULATION APPS AND PHYSICAL TOYS FOR TEACHING EXPERIMENTAL DESIGN PRINCIPLES
}

\author{
Leonard Lye, PEng, PhD, FCSCE, FEC \\ Associate Dean (Graduate Studies) \\ Faculty of Engineering and Applied Science \\ Memorial University of Newfoundland \\ llye@mun.ca
}

\begin{abstract}
Teaching the design and analysis of multifactored experiments to engineers is not an easy task and any help that makes the process of teaching and learning those skills in a way that is hands-on, engaging, and memorable is always welcomed. In this paper, iPhone/iPad apps for simulating multi-factor processes that have been developed specifically for teaching experimental design to engineering students will be described. Examples of physical toys will also be described. Feedback from students and industry experts has been very positive.
\end{abstract}

Keywords: design and analysis of experiments, simulation, iPhone/iPad apps, CEAB, ABET, accreditation.

\section{INTRODUCTION}

The design of engineering systems is rarely accomplished by applying fundamental scientific principles exclusively. In most cases, the design of systems also requires some use of empirical data obtained from experimentation. As such, engineers, scientists, and even businesses carry out experiments in the field, laboratory, computer, or marketplace to discover how different factors may affect the response of the system they are investigating. Often these experiments are multi-factored (have many variables) with multiple responses. Time and budget are also often limited. Most engineers when faced with such multi-factored problems would use the outdated and sometimes disastrous one-factor-at-a-time (OFAT) approach [8]. In fact most engineers, undergraduates or graduates, have very little knowledge on how to properly deal with the design and analysis of multi-factored experiments. Starting in 2014, engineering programs in Canada will be evaluated by the Canadian Engineering Accreditation Board using an outcome based approach [7]. Engineering programs must demonstrate that their graduates possess 12 specific attributes at the time of graduation. One of the graduate attributes is "Investigations" which is defined as "an ability to conduct investigations of complex problems by methods that include appropriate experiments, analysis and interpretation of data, and synthesis of information in order to reach valid conclusions.” This is similar to one of ABET's eleven student outcomes which states that students attain "an ability to design and conduct experiments, as well as to analyze and interpret data" [1]. It was argued in [14] that with the current engineering curriculum of most if not all engineering schools in Canada, it is almost impossible for graduates to possess that stated attribute unless a compulsory course is introduced to specifically teach the proper methodologies for the design and analysis of experiments. Educators and students who think that the skill to design, conduct and analyze experiments of complex problems will somehow be learned in an engineering program, probably do not appreciate fully the myriad of issues that are involved with experimentation to study a complex problem. Many of these issues have been discussed in [14]. It is also likely that they do not know that there exists a whole body of knowledge on the science of experimentation that has been in existence for about 100 years.

It is now recognized that the factorial approach first introduced by R.A. Fisher is the correct and scientific approach in conducting multi-factored experiments [5], [6], [8], [15]. These approaches are now widely disseminated and are having a significant impact throughout industry [9]. However, this has not trickled down to the Canadian engineering curriculum. These approaches such as 2-level factorial designs, fractional factorial designs, mixture designs and response surface methodology are statistically based and can be quite intimidating to the uninitiated. Help is needed in both the teaching and learning process so that these design of experiments or DOE approaches and principles can be taught in a way that is hands-on, fun, and memorable.

In the next section, the advantages of using specially designed toys and simulation programs for teaching experimental design will be discussed. This will be followed in Section 3 by examples of some physical toys and newly developed iPhone/iPad simulation apps 
specifically for teaching experimental design. How these toys and apps can be used in a class will also be briefly discussed. In Section 4, evaluation results and feedback from users of these toys and apps are presented. Concluding remarks are given in Section 5 followed by the acknowledgement and references.

\section{TOYS AND SIMULATION PROGRAMS}

A course on experimental design should not turn into a course on data analysis of experimental data which is often the case. To learn about experimental design, one actually has to do experiments [11]. Incorporating project work in a course is extremely valuable to the students but there are problems too if one is teaching a very large class. Real experiments chosen by the students that are relevant to their research are often time-consuming, and it is also hard to control and grade. This approach is doable and valuable in a smaller class setting especially at a graduate level. Although doing real experiments are rewarding, they can also be costly, time-consuming, cumbersome, and can be utter failures. If there are too many complications from the experiment, then focus is shifted away from the concepts and techniques that need to be taught and illustrated [11].

The use of specially designed "toys" that allow students to conduct multi-factored experiments as a vehicle for teaching and learning design of experiments has been reported with great success by several authors [4], [10], [12], [13], [16].

There are many other simple experiments that have been used successfully for teaching design of experiments. A collection of these experiments is given in [2]. Many of these experiments are simple and meant for junior-high school students. Some are not very practical for use in a large class setting especially if many are to be made. In addition, very few experiments listed have an engineering context. The approach of using simulated experimental data via a computer program is far less common but has more potential and many advantages. Simulated data can be made as realistic as necessary. They can have real advantage over real data when one has specific instructional goals [11]. This is not unlike using a simulator for training jet and airline pilots, operating an excavator, etc. Since it is a computer program, the instructor can easily make the data as clean or as dirty and the user interface can be programmed to represent any engineering system as one likes. A random error term can be added so that data collected by each student will be different which illustrates natural variability of the system. The student's data set can also be combined into a larger scale experiment to investigate the effect of sample size.

\section{PHYSICAL TOYS AND IPHONE/IPAD APPS}

\subsection{Physical toys}

Various physical toys have been described by several authors over the years. These were described in [12] and [13]. Notable ones include the catapult, paper helicopter, and DOE-Golfer ${ }^{\mathrm{TM}}$. More details of these toys can be obtained from [16], [5], and [3], respectively. The author invented the DOE-Golfer ${ }^{\mathrm{TM}}$ (See Figure 1) as an aid when teaching the design and analysis of multi-factored experiments course to graduate students and professional development courses at Memorial University.

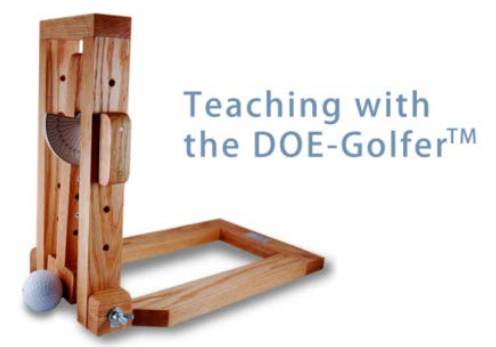

Figure 1: The DOE-Golfer ${ }^{\mathrm{TM}}$

This golfing toy can consider up to 5 or 6 factors e.g. brand of ball, length of club, weight of club, angle of swing, type of greens (carpet), direction, etc. This toy invented in 2003 is sold commercially and used worldwide by numerous large international companies for staff training. Companies using the DOE-Golfer ${ }^{\mathrm{TM}}$ include Bell Canada, John-Deere, Ingersoll-Rand, Fairchild Semiconductor (US and Philippines), Sanofi-Pasteur, Cummins, Eastman Chemicals, Pratt-Whitney (US and Singapore), BMW, ABB (Poland), several universities, and Six-Sigma trainers in US, France, Germany, and UK. It has also been featured in a text book [3]. The key benefit of using a physical toy such as the DOE-Golfer ${ }^{\mathrm{TM}}$ is that the students can use it to collect data after the experimental design, analyze the data, and then apply their results in a competitive team golf tournament. This has been the highlight of the course from the many years of anecdotal evidence and formal evaluations. See Appendix A.

Two software versions of the DOE-Golfer ${ }^{\mathrm{TM}}$, one programmed in Java and another developed for the iPhone/iPad are also available. These can be used during lectures to quickly illustrate a particular experimental design, data collection process, and analysis of the collected data. They are described in the next section. 


\section{2 iPhone/iPad Simulation Apps}

Computer-based simulation programs specifically designed for teaching experimental design principles are few in the public domain unlike the physical toys described above. However some examples were described in [11] which are based on Java applets. However, these applets do not have animation, sound effects, or a nice graphical interface. They are also not easily accessible. Better simulation programs that are fun to use and engaging are required.

Two apps were developed for the iPhone/iPad, both of which are available from the Apple App store as a free download or for a nominal price. The first app is the Golfer app which is the software version of the DOEGolfer $^{\mathrm{TM}}$. A screenshot of the Golfer app is shown in Figure 2.
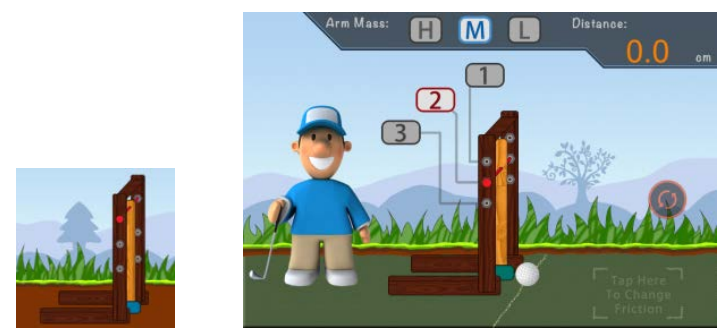

Figure 2: Golfer iPhone/iPad app.

The Golfer app can consider up to 4 factors: length of club, weight of club, angle of swing, and type of green. The response is the distance travelled by the ball. An older Java-based version of the DOE-Golfer simulator is also available by contacting the author.

Another iPhone/iPad app called the DOE-SIM Pro was subsequently developed. It has 10 simulators of various industrial processes. The app is available for sale in the Apple App store. However the app is made available for free for our own students. See Figure 3.

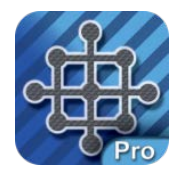

Figure 3: DOE-SIM pro app

The app simulates different multi-factored processes ranging from three input factors to eight input factors. Seven of the simulators have one response and three have dual responses. Some response(s) are nonlinear. The list of simulators available in the app is listed below:
Simulators with one response:

1. Chemical Process (4 factors)

2. Polymer Viscosity (3 factors)

3. Semiconductor Fabrication (5 factors)

4. Concrete Production (5 factors)

5. Drilling Advance Rate (4 factors)

6. Plasma Etching (3 factors)

7. Blue Ball (8 factors)

Simulators with dual responses:

8. Microwave Popcorn (3 factors)

9. Polymer Processing (4 factors)

10. Polymer Conversion (3 factors)

Figure 4 shows screen shot of the opening screen showing the list of simulators available in the DOE-SIM Pro app.

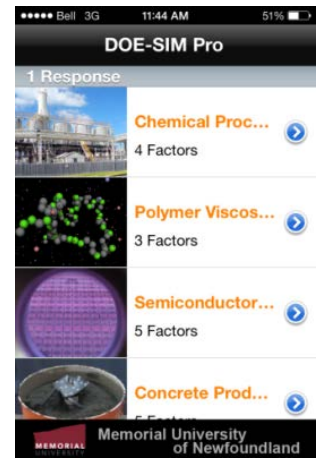

Figure 4: Opening screen of the DOE-SIM Pro app

These simulators can be used in several ways. They are especially useful when used together with excellent DOE software such as Design-Expert by Statease Inc. or JMP by SAS Inc. to set up a designed experiment to test factors and answer the questions in an efficient manner. It can be used by the instructor to generate data from one of the processes based on a certain experimental design. Used this way, the student would analyze the data given, develop the appropriate model, and report on the findings. Another way to use the simulators is to ask students to design the experiment for a given process, collect the data, and then analyze the data they have collected. Data can be simulated to illustrate the simple t-test, one factor ANOVA, general ANOVA, 2-level factorial designs, fractional factorial designs, optimal designs, response surface designs, and multiple-objective optimization. Other concepts such as replications, blocking, and randomization can also be illustrated using the DOE-SIM Pro app. The simulators can also provide a 
convincing way to show why the OFAT approach is less efficient and may not lead to the optimal solution in a multi-factor experiment with factor interactions.

Consider the concrete production simulator with five factors and one response. The screenshot of the simulator is shown in Figure 5.

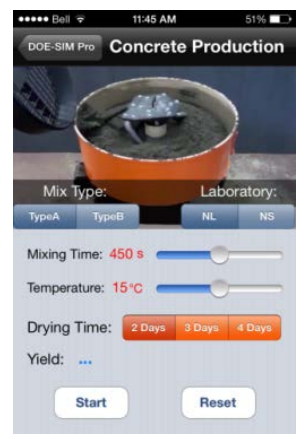

Figure 5: Concrete production simulator

This simulation considers five factors involved in a concrete mix production to determine yield strength:

1. Type of Mix (qualitative)

2. Mixing time (quantitative)

3. Laboratory doing the test (qualitative)

4. Curing Temperature (quantitative)

5. Drying time (quantitative)

A set of typical questions that can be asked of the students include:

- Which is the most important factor that affects the yield strength?

- Are there any statistically insignificant factors?

- Is there an interaction effect between some factors?

- Is the response linear or nonlinear?

- Is a transformation of the response required to meet the assumptions of ANOVA?

- What combination of factors would maximize the yield strength?

To answer the above questions, the students would have to design an experiment taking into account the five factors, collect the data based on the experimental design, analyze the data to determine the effect of each factor and possible interaction effects, develop a prediction model for the response, check for nonlinearity, check the assumptions of ANOVA, and use the model to determine the combination of factors to maximize the yield. Further constraints such as the number of experimental runs, time, etc can also be given to make the problem more challenging and realistic. For simulators with dual responses, such as the Microwave Popcorn simulator, a desired result from the experiment is of course to find out what combination of factors would maximize the taste and minimize the wastage of the microwave popcorn. This would require the student to design an experiment that would allow developing prediction equations for each response and using them in a multi-objective optimization to maximize one objective while minimizing the other.

All the simulators have the appropriate animation and sound effects making them fairly realistic and fun to use. It is just like going to a laboratory and doing a hands-on experiment except that it is done with the iPhone or iPad. It is also faster and cheaper and the process can be projected on a screen when teaching.

\section{EVALUATION AND FEEDBACK}

Evaluation of the DOE-SIM Pro App and DOE-Golfer was carried out during the Fall semester of 2012 and 2013. The survey was conducted among the graduate students who took the graduate course in Similitude, Modelling, and Data Analysis (or Design of Experiments). The survey questions and students' ratings are shown in Appendix A. The sample size was 70 in total. The evaluations were conducted anonymously by a teaching assistant. No ethics approval was required for the study as it was an evaluation and no personal information was requested.

It can be seen that feedback from students was very positive in general. All average ratings are greater than 4 out of 5. In some of the written comments, several students have indicated that the use of more physical toys would be beneficial as these require team work and unfortunately more time consuming especially when the class size is large. The author is currently developing a few more exercises that use a variety of physical toys to include in his classes.

Overall the tools seem to have enhanced the learning of experimental design methodology. To date several hundreds of the apps have been downloaded worldwide. Feedback provided by two experts in the field of DOE about the apps is given below:

"I've just finished playing with DOE-SIM Pro. It's very neat! I plan to demo this in my executive MBA class in a week" - Dr. Christopher J. Nachtsheim, Frank A. Donaldson Chair of Operations Management, University of Minnesota. 
"I downloaded the DOE-SIM app and it works fine on my iPhone 4S. I tried all simulators out and a few settings and they seem to work well. I like the fact that the experiment takes a little longer when you choose the high level of time for the popcorn experiment as opposed to the low level (nice touch). I also like the instructions giving the goal of the experiment and some questions to answer." - Brooks Henderson. Stat-Ease, Inc. Consultant.

\section{CONCLUSION}

The use of physical toys and iPhone/iPad apps for simulating multi-factor processes that have been developed specifically for teaching experimental design to engineering students have been described. The advantages of using these tools for teaching design and analysis of experiments were emphasized. Feedback from students and industry experts has been very positive.

Instructors and students interested in obtaining a free download of the DOE-SIM Pro app can contact the author for a promo code. Java applets and MATLAB versions of the simulators are also available from the author for those who do not own an iPhone or iPad.

\section{Acknowledgement}

I would also like to thank all the students, instructors, and organizations who have tried out my apps and toys over the years. Thanks also go to Memorial University of Newfoundland for an instructional development grant that allowed me to hire Mr. Teng Wang to help develop the simulation apps.

\section{References}

[1] ABET, Accreditation Criteria for Engineering Programs, Engineering Accreditation Commission. www.abet.org. Accessed on December 8, 2013.

[2] Anderson, Mark. DOE It Yourself, available at www.statease.com/pubs/doe-self.pdf. Accessed on December 23, 2013.

[3] Anderson, M. and Whitcomb, P. J., RSM Simplified, Productivity Press, 2005.

[4] Anthony, J., Design of Experiments for Engineers and Scientists, Butterworth-Heinemann, 2006.

[5] Box, G., Hunter, J. S. and Hunter, W. G., Statistics for Experimenters, $2^{\text {nd }}$ Edition, John Wiley and Sons, 2005.

CEEA14; Paper 001

Canmore, AB; June 8-11, 2014

-5 of $6-$
[6] Box, G. and Friends, Improving Almost AnythingIdeas and Essays, Revised Edition, Wiley, 2006.

[7] CEAB, Accreditation Criteria and Procedures, Canadian Engineering Accreditation Board, Engineers Canada, 2010.

[8] Czitrom, V.“One-Factor-At-A-Time Versus Designed Experiments”, The American Statistician, Vol. 53, No. 2, 126-131, 1999.

[9] Dym, C. L., Agogino, A. M., Ozgur, E., Frey, D. D., and Leifer, L. J., "Engineering Design Thinking, Teaching, and Learning”, Journal of Engineering Education, Vol. 94, No. 1, pages 103-120, 2005.

[10] Gunter, B., "Through a Funnel Slowly with Ball Bearing and Insight to Teach Experimental Design”, The American Statistician, Vol. 47, November, 1993.

[11] Lenth, R.V., "Using Simulations in Teaching Experimental Designs", in Proceedings: American Statistical Association Joint Statistical Meetings Section on Statistical Education, 2057-2062, 2002.

[12] Lye, L. M., "Tools and Toys for Teaching Design Of Experiments Methodology”, in Proceedings of the Canadian Society for Civil Engineering Conference, Toronto, Ontario, June, 2005.

[13] Lye, L. M., "Teaching Design of Experiment Methodology Using Toys and Software Tools", in Proceedings CDEN/C $E^{2} E^{2}$ Conference, Hamilton, Canada, 2009.

[14] Lye, L. M., “CEAB's Graduate Attribute 3.1.3: Investigations - Is it really possible for engineering graduates to possess this attribute?", in Proceedings $3^{\text {rd }}$ Canadian Engineering Education Association Annual Conference, Winnipeg, Manitoba, June, 2012.

[15] Montgomery, D. G., Design and Analysis of Experiments, $7^{\text {th }}$ Edition, John Wiley and Sons, 2008.

[16] Schmidt, S. R. and Launsby, R. G., Understanding Industrial Designed Experiments, $4^{\text {th }}$ Edition, Air Academy Press, 2005. 


\section{Appendix A: Evaluation Results of iPhone/iPad Apps and the DOE-Golfer}

In Engineering 9516, you have seen and have used software based and physical toys specifically designed for helping you understand and apply DOE techniques. I would like your feedback on the usefulness of these tools and provide suggestions on how they might be improved. Use the following rating scale:

Rating: $5=$ totally agree to $1=$ totally disagree. Sample size $=70$.

\section{Java Applets/iPhone/iPad Apps}

a) I find the applets/apps easy to use.

b) The applets/apps were fun to use.

c) The applets/apps helped my understanding of experimental design.

d) The applets/apps helped my understanding of random variations.

e) Collecting my own data using the applets/apps helped me better understand where the data came from.

f) The applets/apps provided a sufficient variety of experiments for teaching and learning purposes.

\section{DOE-Golfer (used in golf tournament)}

g) The use of the golfer was good for team-building

h) Use of the golfer enhanced my understanding of RSM techniques.

i) The golf tournament provided a fun way to learn DOE

j) I understand process variation better after using the golfer.

\section{Overall use of applets/apps and toys}

k) The combined use of the applets/apps and golfer have helped in the understanding and application of DOE techniques.

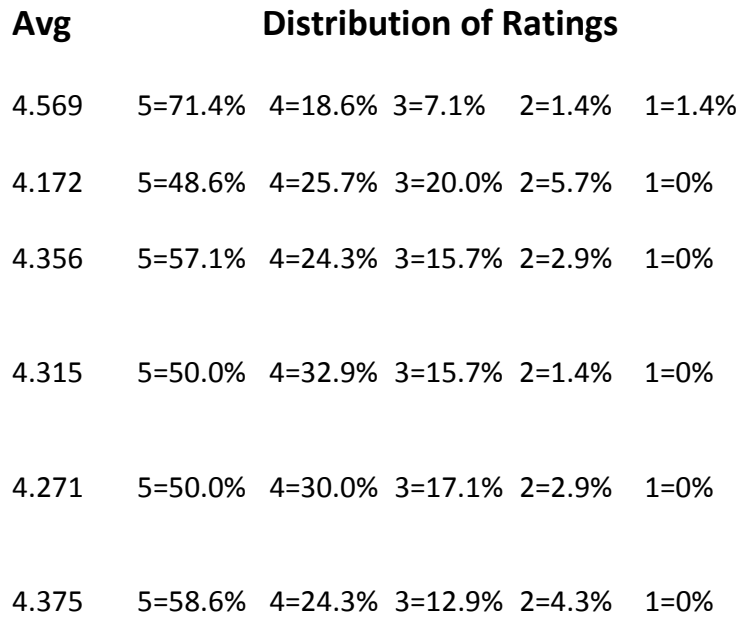

